\title{
Luciano and His Shining Star Backpack
}

Alejandra Santana López • Claudia González Romero

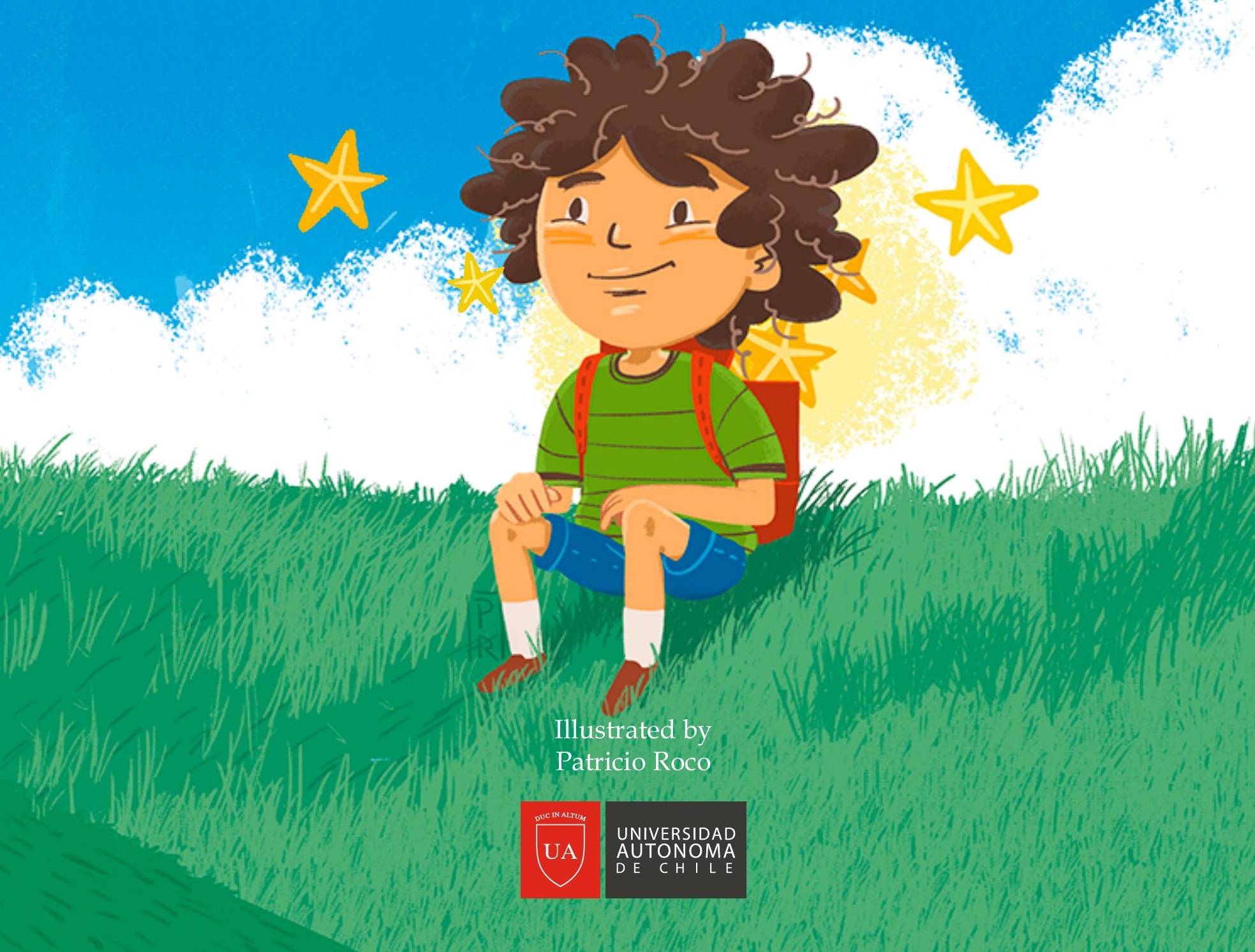


in

10

-

筧

1

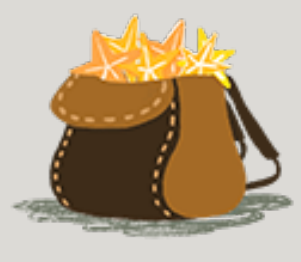

1

I

i

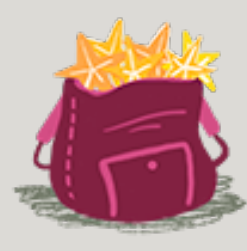

$\theta$

술

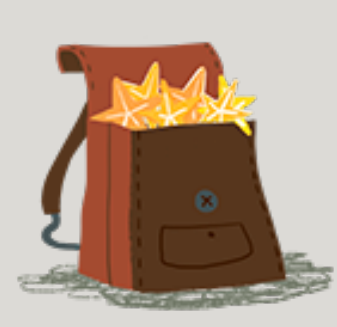

II

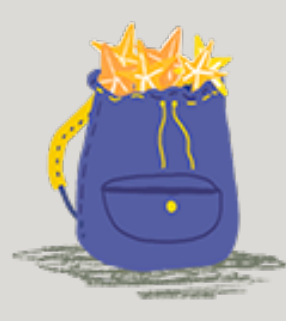

I

统

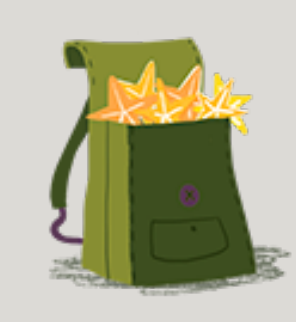

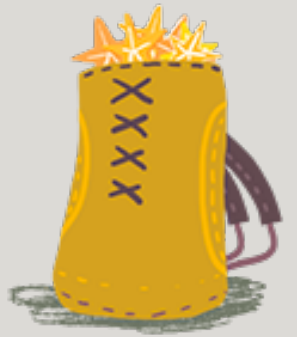

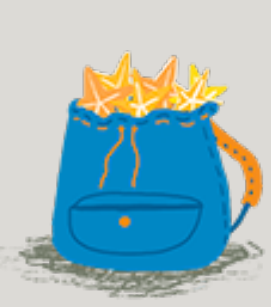

in

配

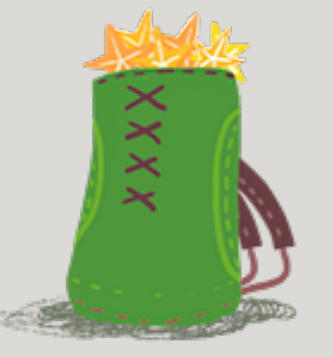

U)

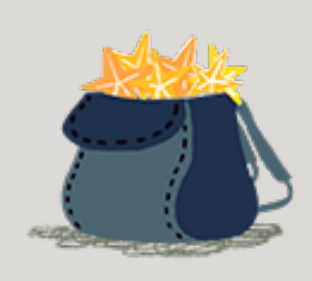


OUniversidad Autónoma de Chile.

Centro de Comunicación de las Ciencias (Science Communication Center) http://ciencias.uautonoma.cl

Authors: Alejandra Santana López and Claudia González Romero

Editorial Director: Isidora Sesnic Humeres

Illustration and Design: Patricio Roco Urverta

Translation: Maria Cognata

ISBN: 978-956-8454-43-2

Intellectual Property Registration Number: 308528

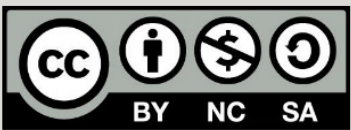

This material may be distributed, copied, and exhibited if the credits are shown and only for educational and scientific outreach purposes. It is not allowed to receive any commercial benefit, and the derived work must be under the same licensing terms as the original work.
To Jaime, my dad, a little boy with curly, black hair who plays in the southern forests of Chile.

Alejandra

To my little monkeys, who grow with the generosity that lights up their minds and the love that guides their hearts.

Claudia

To Uriel Parker, who had faith and left behind his backpack full of stars, and for Luz Cabrera, for being the one who passionately makes them shine today.

Alejandra y Claudia 


\section{Luciano and $\mathrm{His}$ Shining Star Backpack}

Alejandra Santana López • Claudia González Romero

For those who believe in donating organs and its opportunity to give the gift of life.

For those who have thought about the possibility of being an organ donor, their families, and their loved ones.

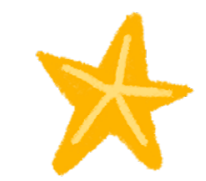

Illustrated by

Patricio Roco 
Starburst is a very special planet in a galaxy far, far away. On this planet, people carry a backpack full of stars which lets them live full lives.

These stars give people the energy and excitement they need to laugh, jump, share, and be happy.

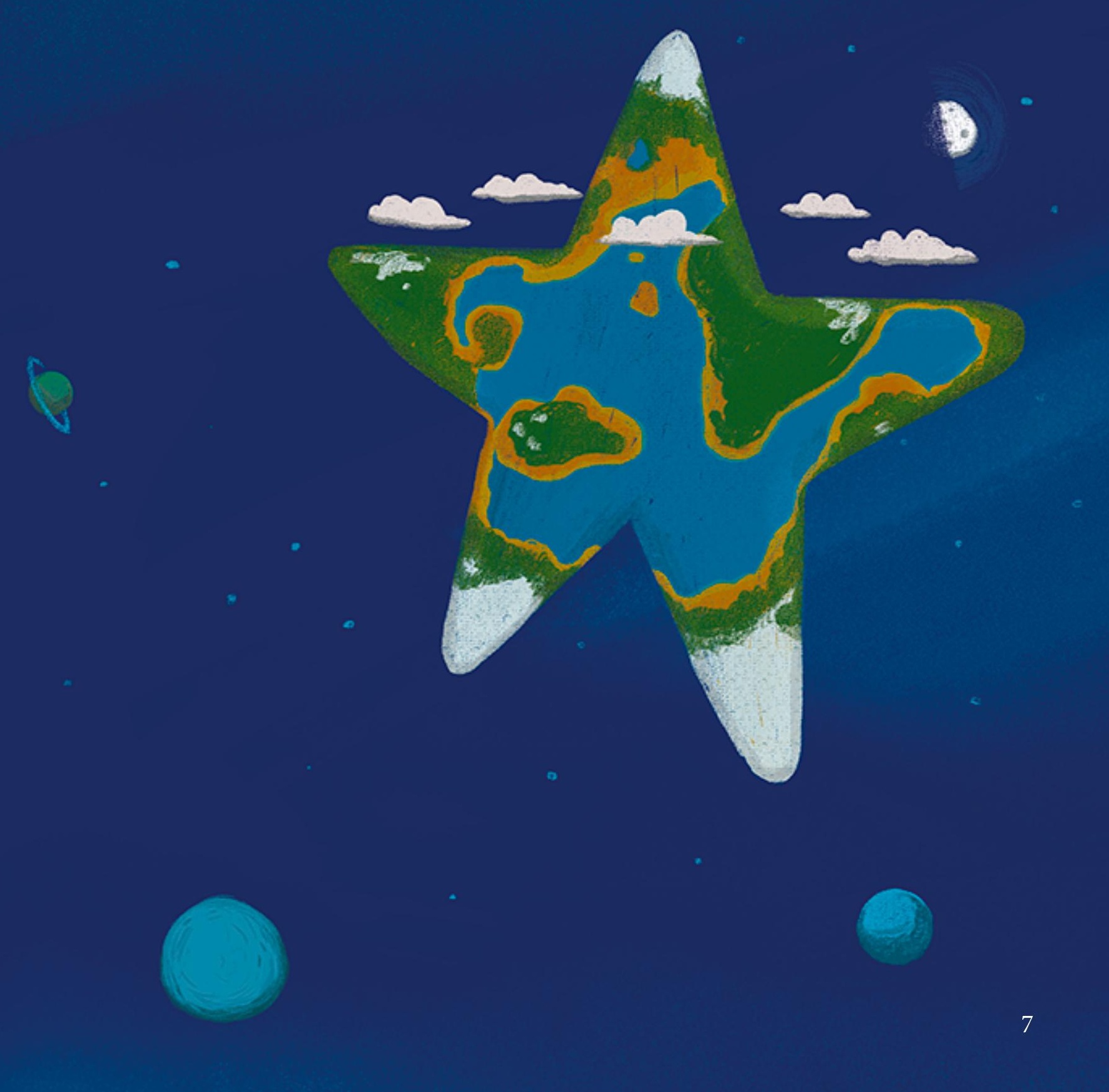


One day, coming home from school, Luciano found a letter in the mailbox outside of his house. It was an invitation from the planet Love Supreme, and it said:

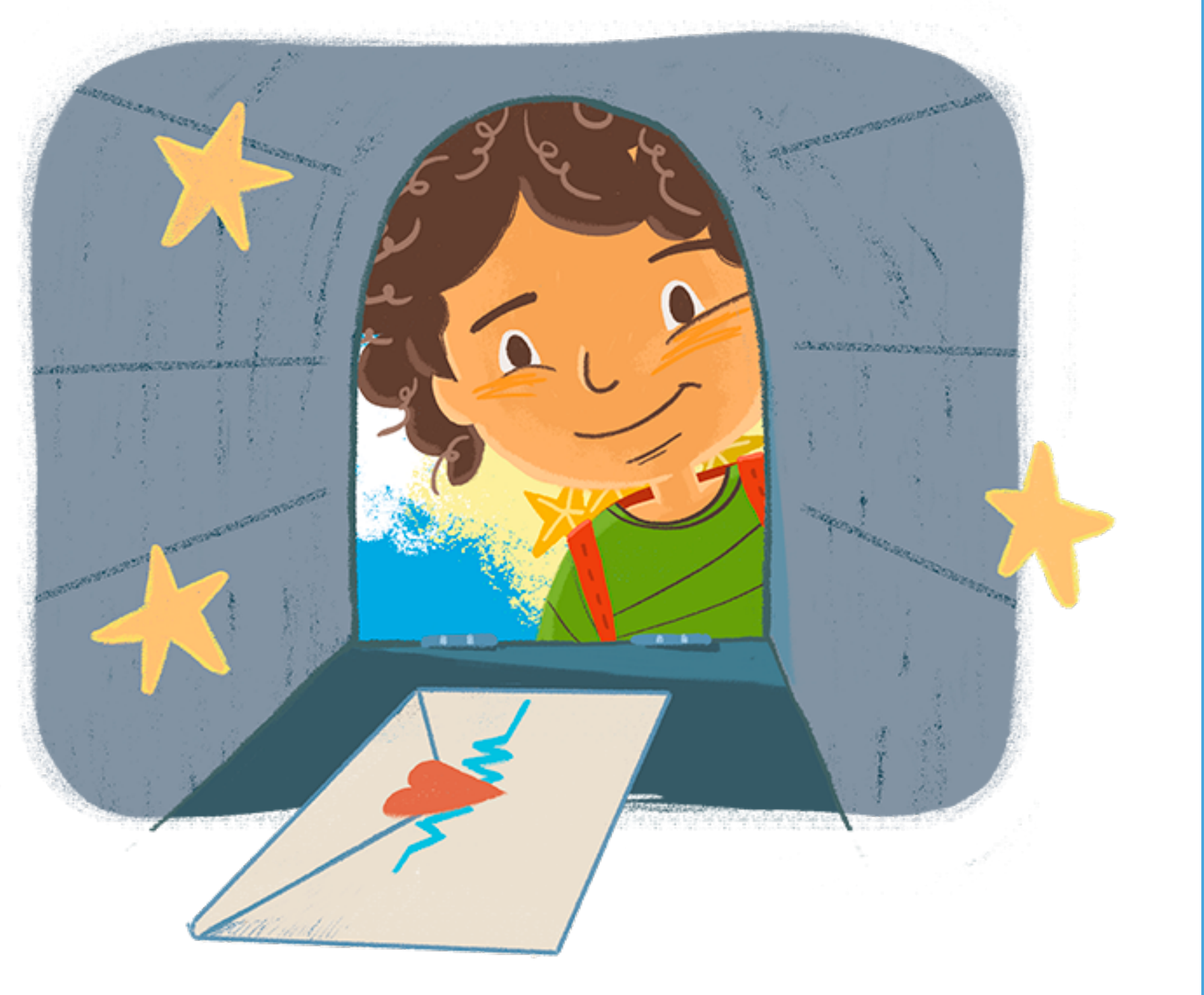

Dear Luciano,

Planet Love Supreme needs young people that are happy and enjoy life very much, like you. We have watched you, and we believe that you would be an excellent friend and a big help to the children here. We invite you to come and meet us and spend time with our inhabitants. Before coming, you need to know that, upon arrival, you must get rid of your shining. star backpack. You will not need it here. All you need is the shine in your eyes.

We will be waiting for you.

Lots of love, 


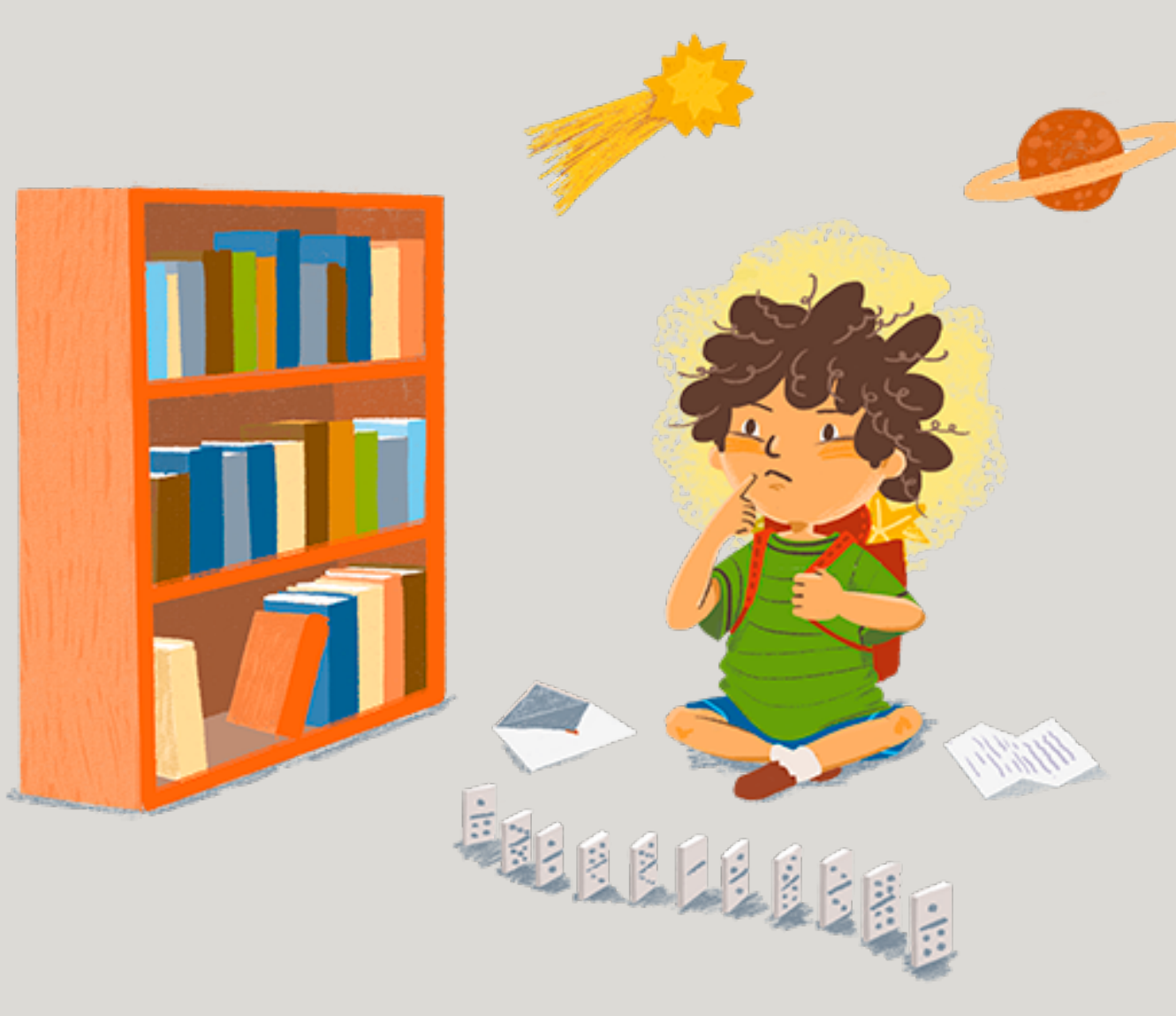

Luciano couldn't stop thinking about that invitation. He was very adventurous, and the idea of traveling to other planets fascinated him, however, he had so many questions in his head. Would it be very different living without his star backpack? How would he play with other children? Maybe it would feel lighter, freer, he thought, maybe he could do a lot of new things...
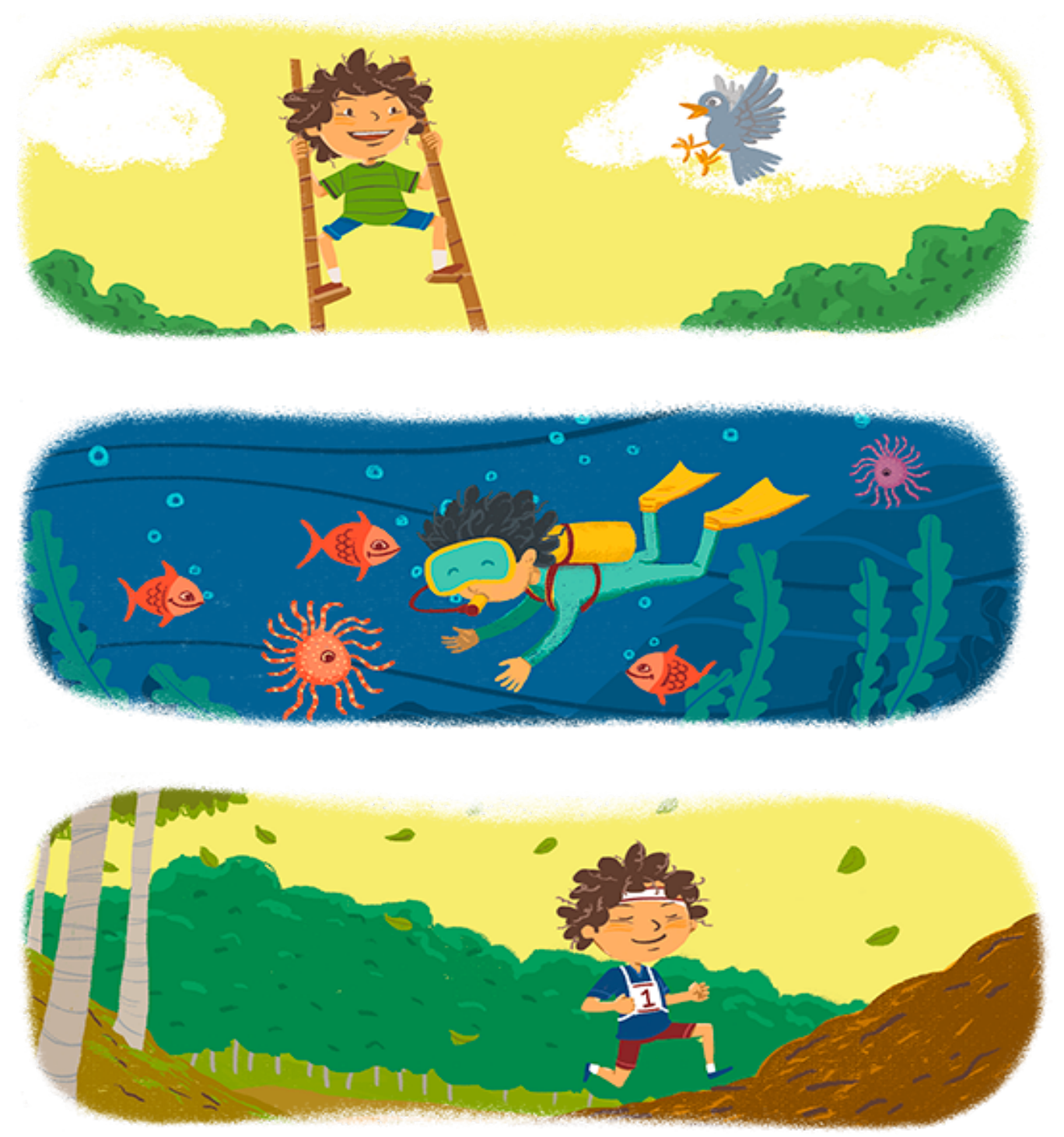

"I've made my decision. I'm going to go to Love Supreme," said Luciano. "And now, I must prepare for the journey." 
Meanwhile, Luciano kept asking himself what he would do with his backpack, where he would leave it, or who would he give it to. He loved that backpack full of shining stars, so he had to make sure he left it in good hands.

One day before his journey, Luciano said to his mom, "I'll leave my backpack and stars with you so that they light up your days, and you will always remember me. As long as you share them, they will never stop shining, and I will live on through them."

Then, after giving her son a big hug, Stella White took the backpack.

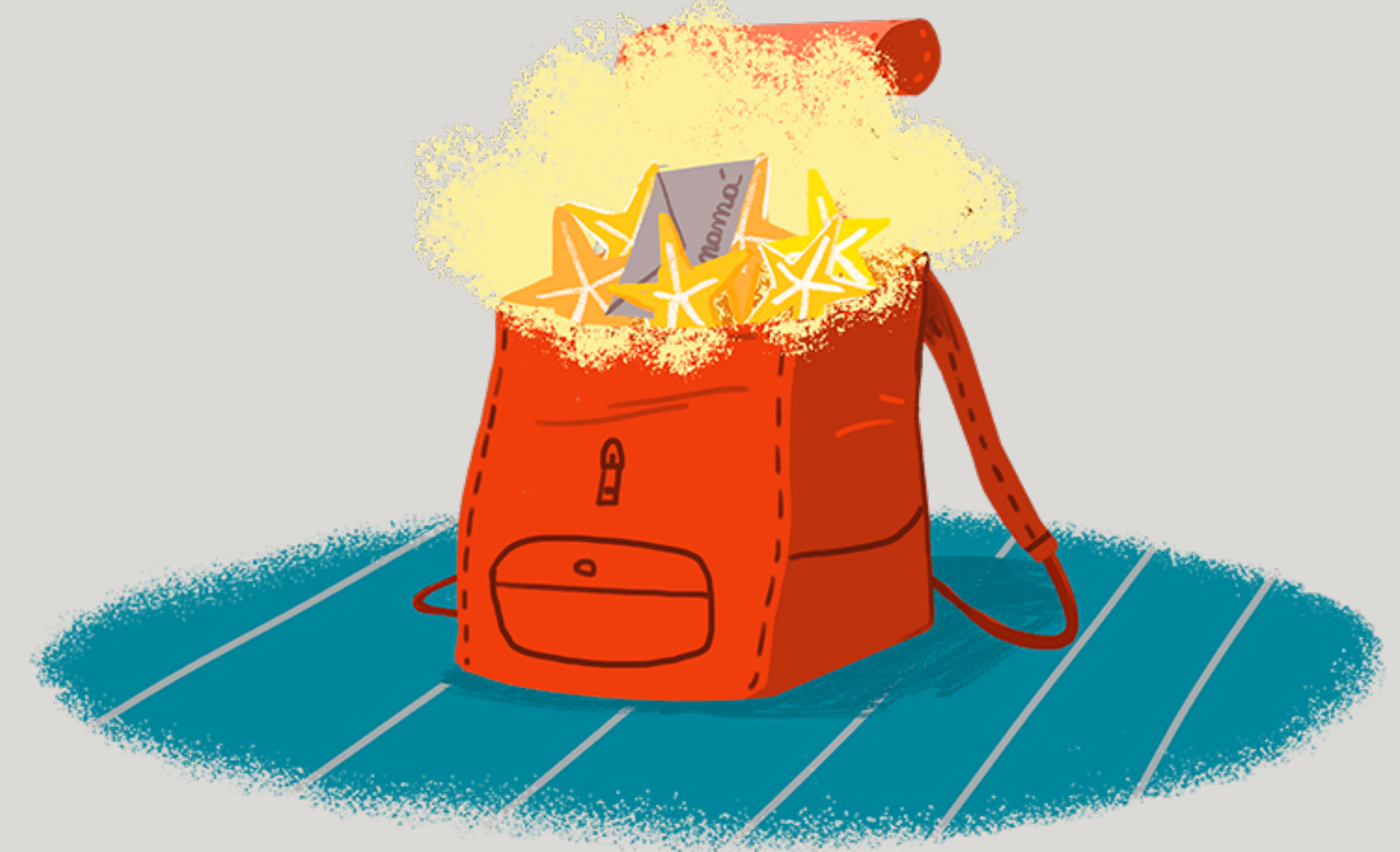




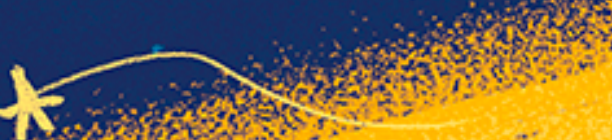

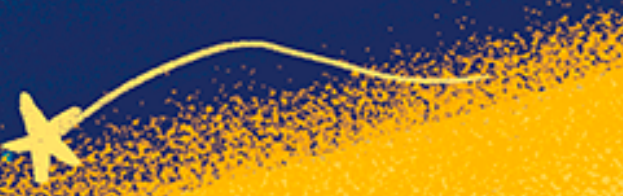

ton

And the day of the big journey arrived.

Full of excitement, Luciano gave his parents and siblings goodbye hugs and kisses, and when the night fell, he got up on the shooting star which would bring him to Love Supreme.

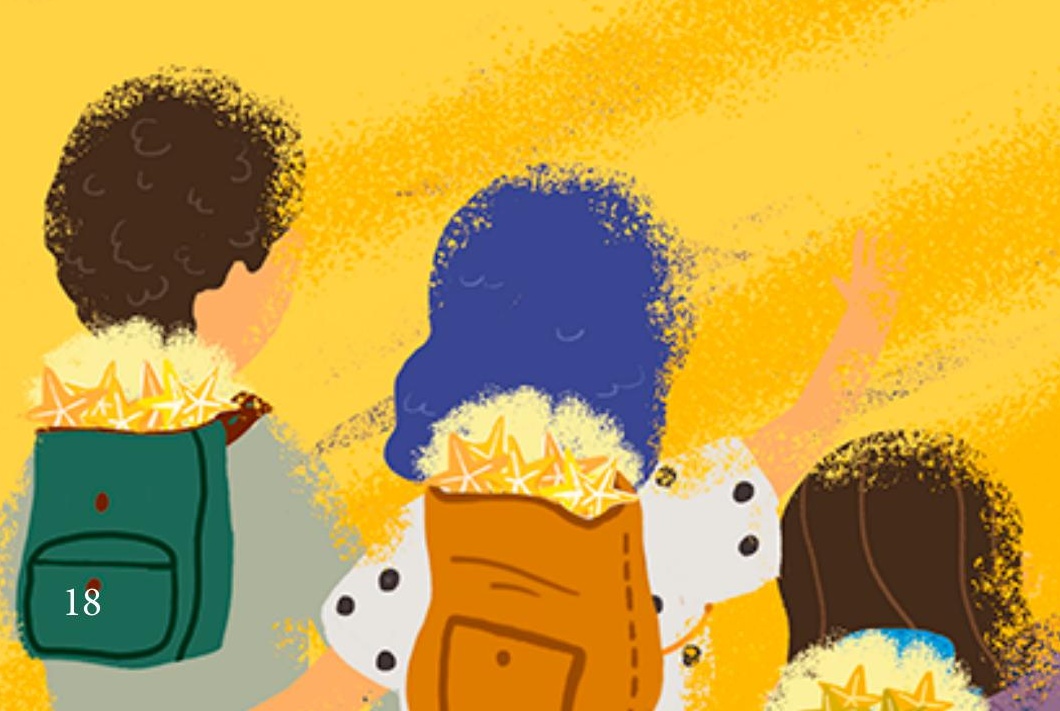




\section{$\star$}

The next day, walking through the park, Stella White ran into Lucy Sparkles, a girl who lived in a nearby neighborhood.

Lucy was happy, with a soft smile and a graceful walk. Although she was always smiling, the stars that she carried in her backpack were very delicate, and, sometimes, they even seemed to be burnt out. They were so delicate that she always had to be alert and careful when playing with the other children.

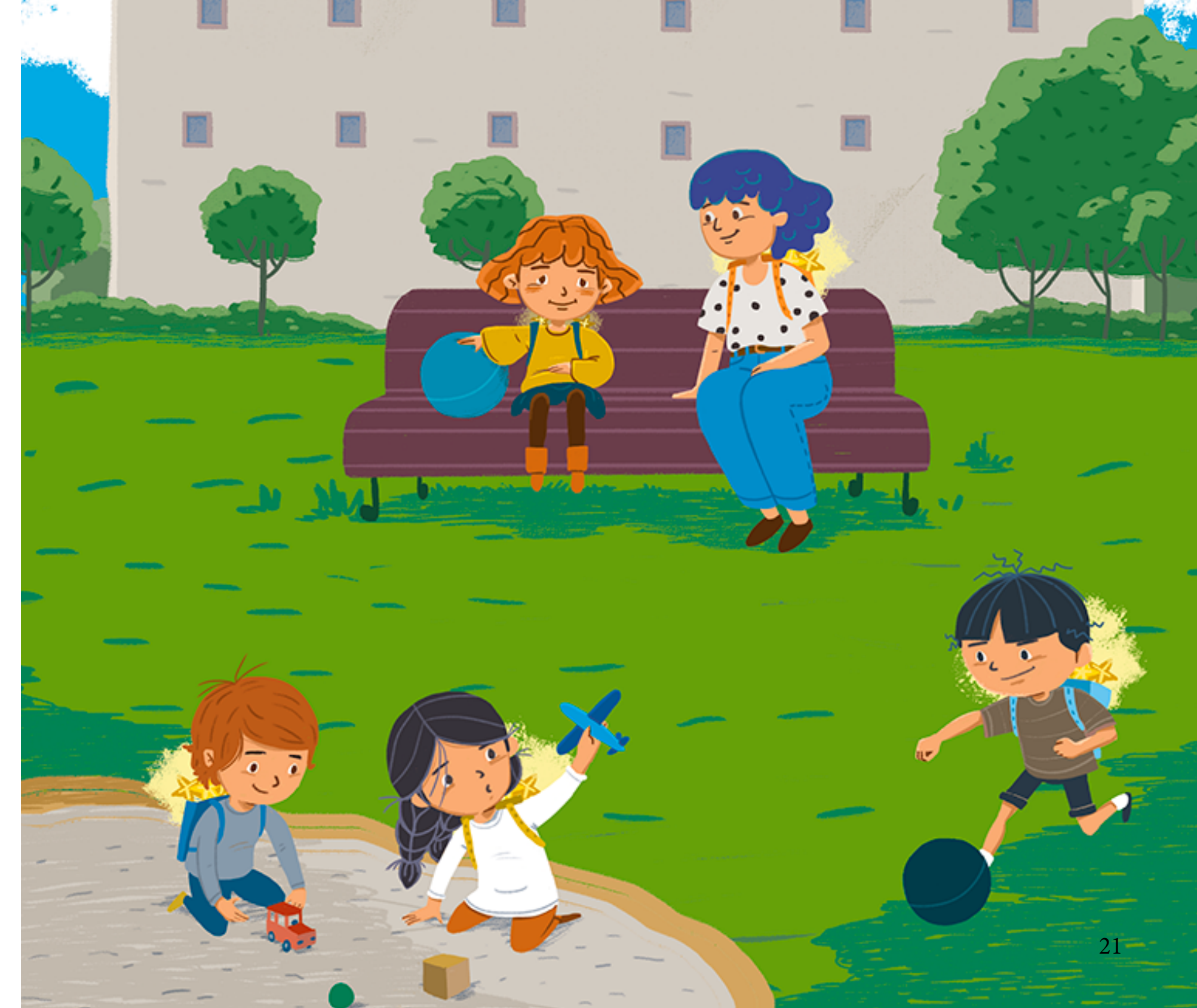




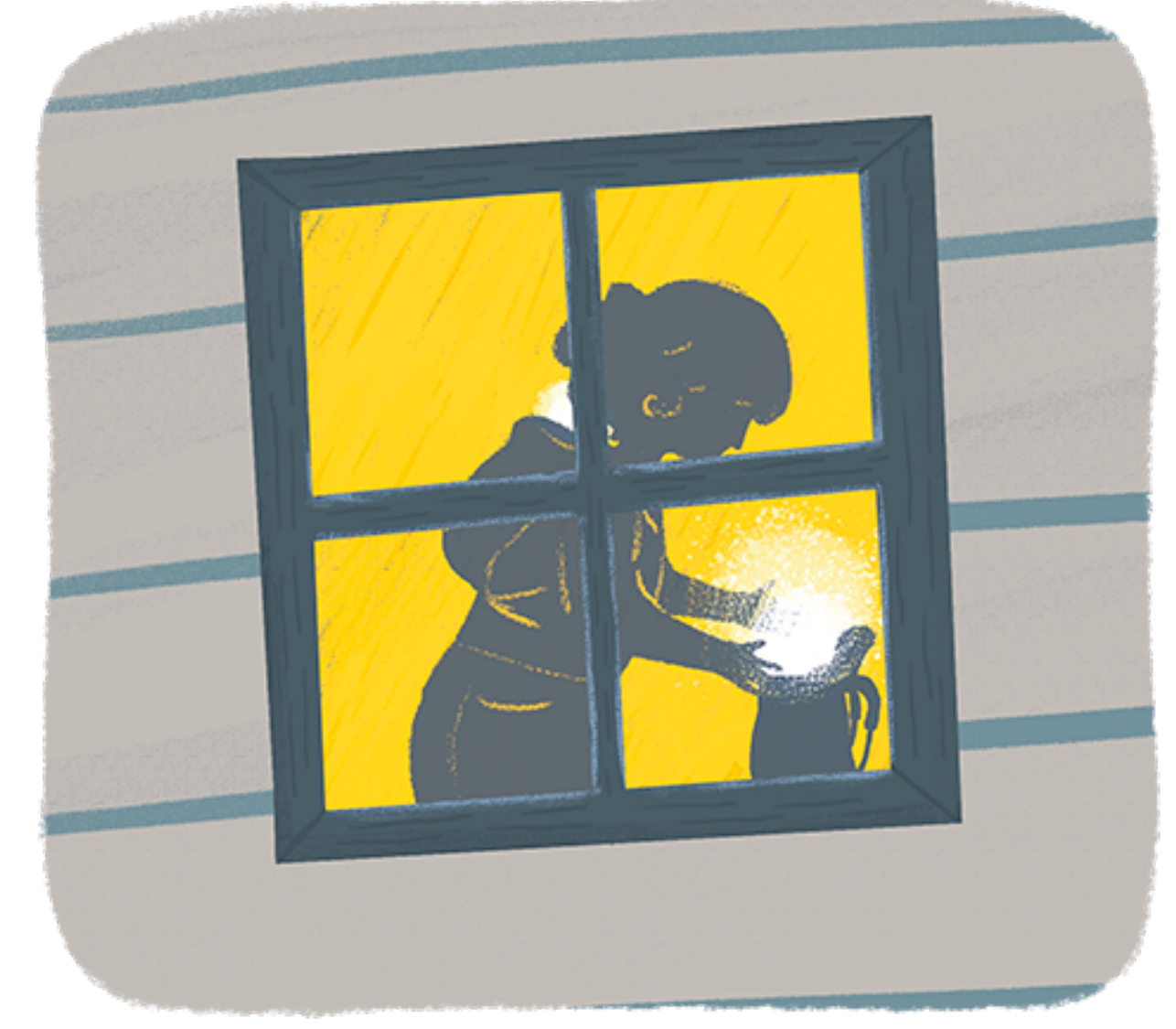

When she arrived home, Ms. White looked for Luciano's backpack. She had an idea in mind, but first, she needed to check how many stars there were and if they still shined with the same intensity.

When she opened the backpack, she found a great surprise. Luciano had left behind a letter.
These stars will keep on shining, and I will keep on shining through them only if someone else carries this backpack, and it must be someone who is able to feel the happiness that I felt when $J$ used it. There is no greater happiness than sharing.

$$
\text { Luciano Lightbacon. }
$$




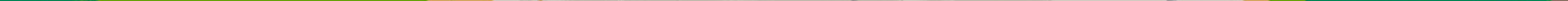


Luciano, who was happily living on the planet Love Supreme, saw through a magic spyglass how his stars kept shining thanks to the use that Lucy Sparkles gave them.

He and Lucy would be connected forever by the magical shine of those stars.

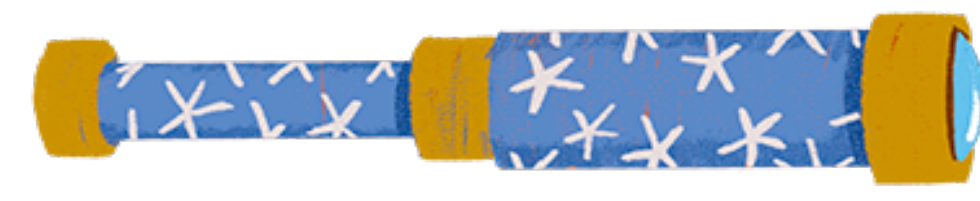

\section{The End}




\section{About the authors}
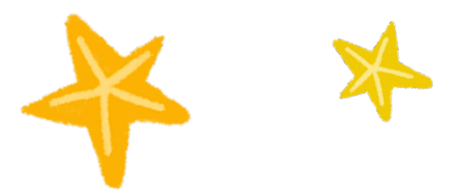

"One day, you, Lucy, or I will also be invited to the planet Love Supreme, where the inhabitants don't need a backpack. All they need is the look of love in their eyes."

Alejandra Santana López

Social worker, Master of Psychology and Education, Doctor of Science Education. Research associate of the Universidad Autónoma de Chile and social work

professor at the same university. She has dedicated herself to university teaching, social intervention, and research at a range of Chilean universities. Her areas of interest are childhood, family, schooling, and poverty. Currently, she does work research ethics in social sciences, arts, and humanities. Contact: alejandrasanta@gmail.com

Special education teacher, Master of Education Management. She has taught in the classroom and has worked for the Unidad Técnico Pedagógica (Curriculum and Instruction Specialists Agency) and in management for different

establishments. Today, she works as an advisor for the Unidad de Supervisión Técnico Pedagógica (Curriculum and Instruction Specialists Supervision Agency), a division of SEREMI of the Ministry of Education. Her areas of interest include education, vulnerability, childhood, and leadership. Contact: gonzalezromeroclau@gmail.com 


\section{Reading mediation guide}

To guide adult-mediated reading, different strategies are developed that make it easier for the child to understand a subject as important and sensitive as organ donation while enjoying the literary text and illustrations.

\section{READING PREPARATION}

It is important to read the story several times before presenting it to the children to know its various components and be able to handle said components well. This includes both knowing and understanding the characters as well as the meaning and emphasis, which will allow the narrator to carry out an appropriate interpretation using intonation and pauses.

\section{BEFORE READING}

In a comfortable, story-telling environment, show the children the front cover using the "text interrogation" strategy (Jolibert, 1992), which can be done by asking the following questions: What do you think this story will be about? How do you think these children feel? What do you think about them?

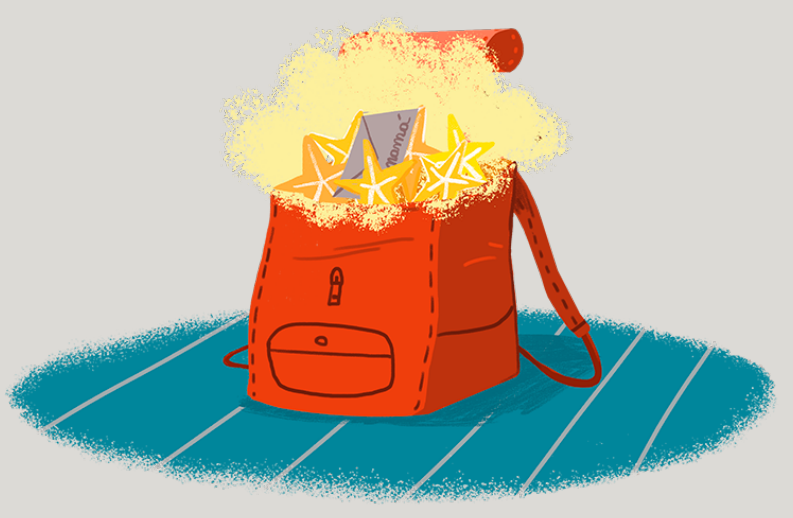

\section{DURING THE READING}

Using an appropriate tone of voice according to what the story indicates, remember the different intonations and pauses to ask questions such as:

What was Luciano's backpack like? Could we compare Luciano's backpack with an organ in our body? (page 17)

How did Luciano feel the moment when he got on the star? (page 19)

Why wasn't Lucy Sparkles able to play with her friends? (page 21)

What did Luciano's mom do with the backpack he left her? (page 25)

What happened to Lucy Sparkles when she received Luciano's backpack? (page 27)

\section{AFTER THE READING}

Encourage the children to give a summary of what they heard to be sure that they understood the story. Also, you can ask questions regarding their values or criticisms such as:

What do you think about Luciano asking his mom to give away his backpack?

What would you have done if you were Luciano?

What do you think about Luciano's mom giving his backpack to Lucy Sparkles?

\section{REFERENCES}

Plan Nacional de Fomento de la Lectura, 2010. (National Reading Promotion Plan, 2010.) 
in

10

-

离

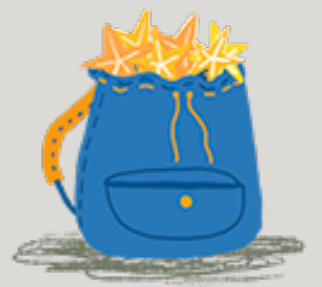

e

10

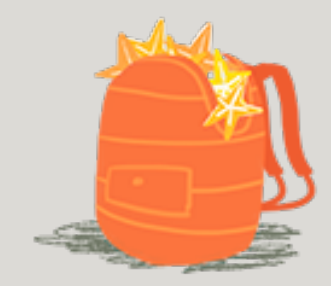

g.

-

$\theta$

i

1

(a)

e

I

s

I

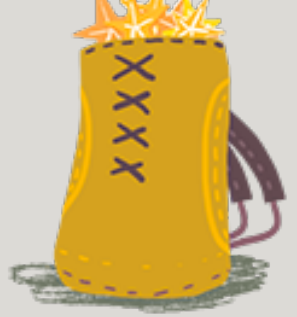

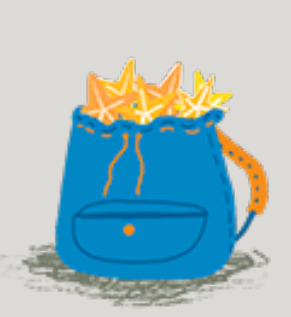

但

달

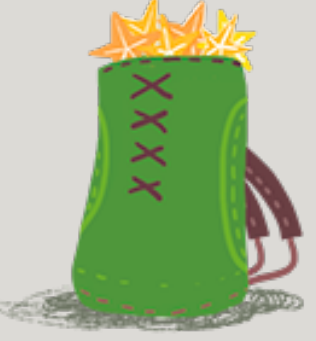

U

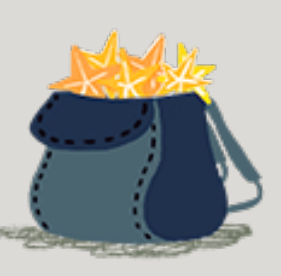


Luciano and His Shining Star Backpack sets out to help children understand the experience of organ donation through a metaphor that facilitates the integration of this life lesson into the children's world, exploring scenarios and emotions that connect the reader with transcendence and solidarity.

This book is a publication of the Centro de Comunicación de las Ciencias (Science Communication Center) of the Universidad Autónoma de Chile and can be downloaded for free on the website ciencias.uautonoma.cl

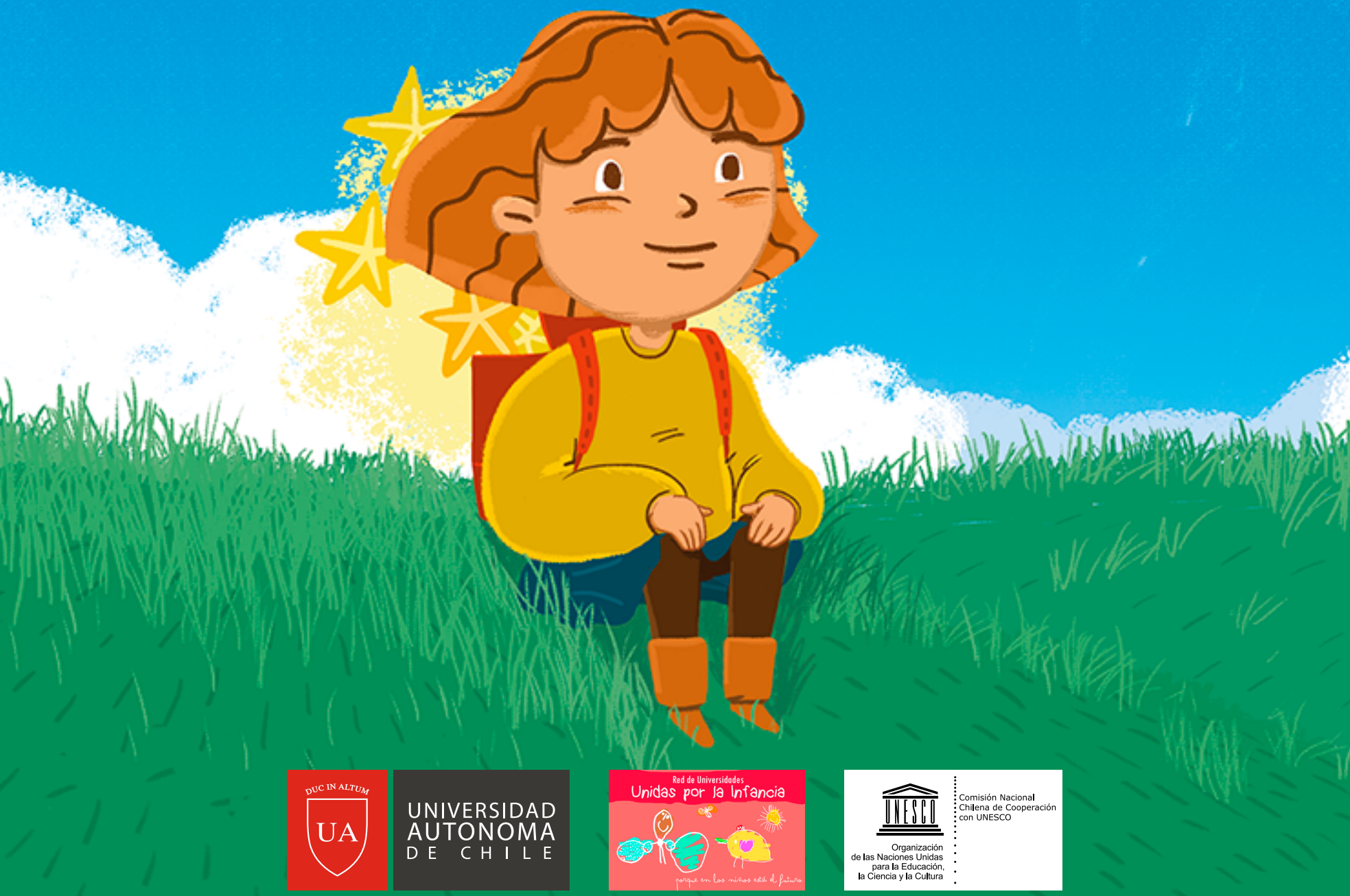

